\title{
Design and performance testing of liquid separation fryer
}

\author{
Wilawan Trijid ${ }^{1}$, Tipapon Khamdaeng ${ }^{1}$, Thanasit Wongsiriamnuay $^{1}$, and Numpon

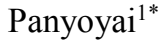 \\ ${ }^{1}$ Maejo University, Faculty of Engineering and Agro-Industry, Agricultural Engineering Program, \\ 63 Chiangmai-Phrao Road, Nonghan, Sansai, Chiangmai, 50290, Thailand.
}

\begin{abstract}
This study presents a liquid separation fryer using the principle of heat transfer between different liquids, oil, and water, to be used as a hot and cold fluid in the frying process, respectively. It causes small pieces of food to fall into the water zone, causing no burns, which causes the fried oil not to be black and smokeless while cooking. This study was comparing the efficiency of the frying results between the liquid separation fryer with the conventional frying pans at the same process is $180^{\circ} \mathrm{C}$ of oil temperature, use the polar test set to measure the quality of the oil. The results found that the number of frying process in liquid separation fryer has 27 times more than regarding the amount of an extreme in used by conventional frying pans. From the prototype experiment, the fuel frying rate was reduced by $16.79 \%$, causing the production cost to decrease by $20.6 \%$. The production volume was more than $20.1 \%$ than the conventional pan; because of this, the liquid separation fryer has a temperature-controlled to save the amount of gas used.
\end{abstract}

\section{Introduction}

Food is an essential factor in living, and getting good food affects the health of people. Data from the Ministry of Public Health in 2009 found that Thai people with high blood pressure have 981.48 people per hundred thousand people. In which high blood pressure is associated with circulatory system diseases such as heart disease, coronary artery disease, and brain veins. Are all caused by the nature of life in which food is one of the most important causes, especially cancer. The food that is popular among consumers for a wide range of satisfaction in flavor, smell, fragrance, and the texture is crispy and juicy with the water inside of the food pieces [1]. The fact that the use of oil in the food of entrepreneurs at all levels is the oil that has been fried food in the form of repeatedly cooking, which will change or add new oil to maintain food features only. It has a simple observation principle, such as oil that is used for frying food, has black, black smoke, viscous, fouling, and foaming. These characteristics are the basis for an oil change. The frying means cooking food by using vegetable oil or animal fat as a medium for heat exchange. Food processing by using heat is a prevalent method, which is one of the ways of food preservation, with the primary purpose of inhibiting

\footnotetext{
* Corresponding author: n.panyoyai@gmail.com
} 
food spoilage and inhibiting the activity of the enzymes present in food, including parasites and various insects [2]. Frying means putting food pieces in the oil while warm. The temperature surface of the food will rapidly rise. It was causing the water that is the main ingredient in the diet, to evaporate. The outer food skin will become dry. The characteristics similar to baking or grilling, evaporation of water will gradually be moving into the inside of the food piece, resulting in a dry skin covering the food. The primary purpose of frying is to change the quality of food consumption. The secondary objective is to preserve food, destroying microorganisms, enzymes, and reducing water activity on the surface of the food or throughout the diet [3]. The most quality of the final product of food is much dependent on the main processes are a combination of simultaneous cooking and drying processes [4]. The deep-frying process is the primary method for food preparation and is commonly preferred by the fast-food industry [5,6]. The process is described as more complicated because of the physical and chemical property of frying oils were changed during heating at $150-190^{\circ} \mathrm{C}$ [7]. These changes occur similarity of the autoxidation, thermoxidation, pyrolysis [8-11], and polymerization reactions, and a wide range of undesired degradation compounds have been detected in frying oils [12-14]. From the study conducted in general market surveys, most of the original oil is used for cooking more than once, resulting in deterioration of the oil that may cause the number of polar compounds to exceed 25 percent of the weight. Frying causes the color of the oil to become more intense and makes the food that was fried has a distinct color change. It can be seen that frying using a conventional pan makes the oil performance deteriorate. There fore when there is a process of duplication, the technology for the exchange of incomplete heat between different types of liquids was applied to the liquid separation fryer. The objective of this study makes the frying machine more efficient and with the cost that is suitable for fried food processing. It is, therefore, intend to test the performance of liquid separation fryer.

\section{Materials and methods}

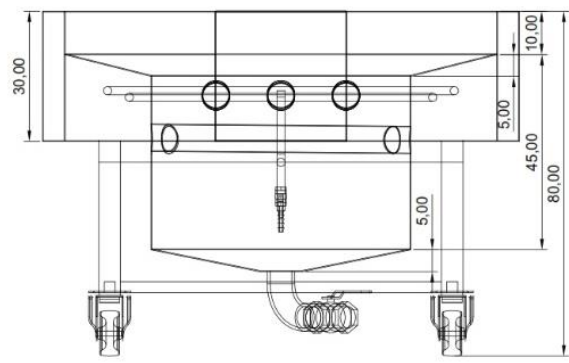

Fig. 1. Structure of liquid separation fryer.

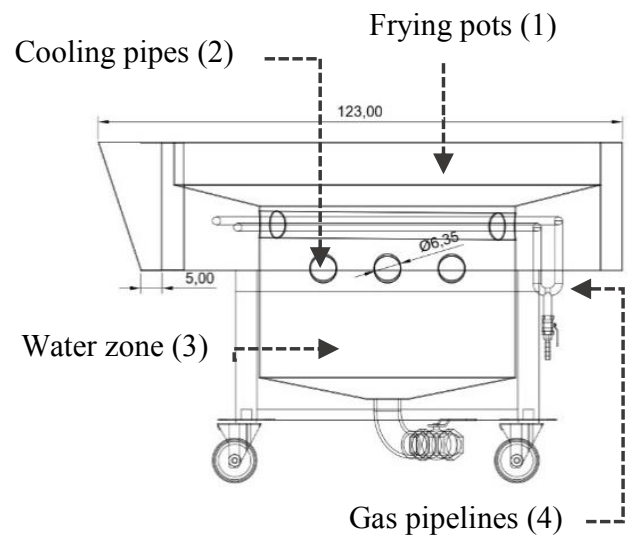

\subsection{Materials and chemicals used for testing}

This section considers the materials and methods utilized in the execution of the study. The liquid separation fryer consist of the size of the tank used for frying is made of stainless steel that is $100 \times 80 \times 50 \mathrm{~cm}$. (Figure 1). The gas pipelines (4) built around the container tank of oil upper water zone (3). The control unit used to control the gas system with an electric system that can set the temperature and maintain a constant value. The oil zone or frying pots (1) was contain frying oil that can measure polar values by using the chemical of polar test kit in frying oil to see oil deterioration after the frying process. Chemicals used to test the reaction 
with charged compounds in the frying oil sample; it gives a light pink to dark pink color when the number of polar material is not more than $25 \%$ and without pink color when the number of polar material is greater than $25 \%$.

\subsection{Method}

Liquid separation fryer consisting of structural design in the base part, frying pots (1), gas pipelines (4), cooling pipes (2), electrical systems for control temperature, and the point of sticking gas, as shown in Figure 1. The part of the pot will work together between water and oil. The oil will float on the top of frying pots, and the water will be at the bottom of the water zone with the installation of a gas point system that heats at $180^{\circ} \mathrm{C}$. In the frying pots when the process of incomplete heat exchange of different types of liquids occurs, so the water temperature is around $30-40^{\circ} \mathrm{C}$. For this reason, some food waste or sediment will be pulled down to the bottom of the water zone, causing no burning of food waste; it makes the oil smokeless and reduces polar formation. The advantage is that it can fry food at a long time, constant temperature of frying oil, slow black frying oil, and fuel economy, as shown in Figure 2.

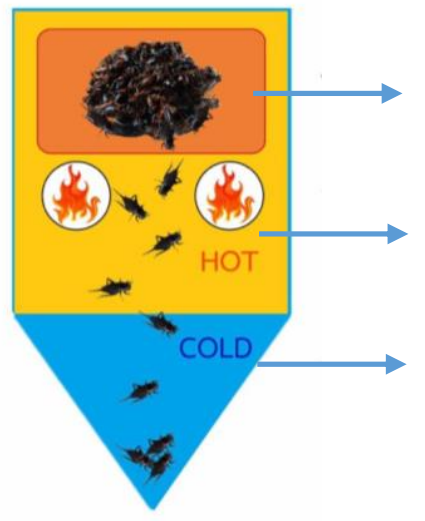

Area for frying.

The heating area of oil for frying.

The sediment area in the water section(low temperature) causes the sediment not to burn.

Fig. 2. The separate frying system

The prepared be fried with a liquid separation fryer by control temperature at $180^{\circ} \mathrm{C}$ (which is the suitable temperature for frying the product) using a Palm oil of $70 \mathrm{~L}$ per $82.50 \mathrm{~L}$ of water. This study focuses on the influence of incomplete heat exchange processes of different types of fluids, the number of polar compounds in the frying oil, waste fuel to test the effectiveness of liquid separation fryer. The phenomenal heat exchange occurs when entering the frying process. The moisture in the product will be replaced by oil and evaporated. Then the moisture floating in the air, mixed with oil, then falling into the water, as well as food waste or sediment, causing no burning of food, oil is not black, smokeless, and does not require a filter. When frying food for a long time, there will be a large number of polar compounds. The water is a polar bear with the same polarity, thus helping to reduce polar compounds because the frying machine is equipped with a gas control device with an electric system that can be adjusted to a constant temperature and helps reduce fuel consumption. From initial testing factors, performance indicators are the number of polar compounds in the frying oil. By using a test kit by adding polar drops to the sample test tube of four drops, then add two drops of oil sample to the sample test tube and close the test tube tightly and shake for $30 \mathrm{~s}$ and immediately translate the results. The amount of fuel lost is 
determined by the amount of gas before frying, compared with the amount of gas after frying, whether it is worth the use of fuel or not, considering the amount of fuel used for testing,

Analysis to determine \%Product Yield [15]

$$
\% \text { Product Yield }=\frac{\text { Output }}{\text { Input }} \times 100
$$

\section{Results and discussion}

\subsection{Polar test results in frying oil}

The polar content testing in experiments by liquid separation fryer with conventional frying pans will consume $70 \mathrm{~L}$ of oil per $3 \mathrm{~kg}$ of product. It is using oil samples after the frying process at 5, 10, 15, 20, and 25 times to test for polar content by a polar test kit. From the experiment study, it can be seen that there is a change in color in the oil of the test kit, as shown in Table 1 .

Table 1. The polar test of frying oil.

\begin{tabular}{|c|c|c|}
\hline \multirow{2}{*}{$\begin{array}{c}\text { Example } \\
\text { no. }\end{array}$} & Pan & Polar test results in oil \\
\cline { 2 - 4 } & Prototype frying machine \\
\hline 5 & Polar compounds in the range of $1-10 \%$ & Polar compounds in the range of $1-10 \%$ \\
\hline 10 & Polar compounds in the range of $11-20 \%$ & Polar compounds in the range of $1-10 \%$ \\
\hline 15 & Polar compounds in the range of $21-24 \%$ & Polar compounds in the range of $1-10 \%$ \\
\hline 20 & Polar compounds in the range of $21-24 \%$ & Polar compounds in the range of $11-20 \%$ \\
\hline 25 & Polar substances exceeding $25 \%$ & Polar compounds in the range of $21-24 \%$ \\
\hline 27 & & Polar substances exceeding $25 \%$ \\
\hline
\end{tabular}

Note

Polarity $1-10 \%$ is available.

Polarity $11-20 \%$ the oil is still available, should not add new oil.

Polarity $21-24 \%$ is still oil that should not be added.

Polar compounds over $25 \%$ are the oil that has deteriorated and should not be used.

From the test of polar compounds in the oil, repeated frying, compare the conventional pan with a liquid separation fryer. It was found that the liquid separation fryer can maintain the quality of fried oil repeatedly than the conventional pan. Due to the amount of polar substance in the oil of the conventional pan exceed $25 \%$ of polar compounds in the frying oil, repeat 25 times, and there was a change in color. At the same time, the liquid separation fryer has not changed the oil in the polar test set. The frying oil of the prototype fryer can still be used until the polar content exceeds $25 \%$ at 27 times. The frying machine has designed a system of separating the two liquid layers in the frying process. 
The development of this research was used water as an aid of oil polar compounds value to be used for a more extended period. The water was used to separate the residue particles in the oil and also helps to prevent black oil from burning of food particles. The originality knowledge of this research was the developed deep-frying process. The designed system of separating two liquid layers could maintain the quality of the palm oil and can be used for a more extended period and is not harmful to consumers such as cancer.

\subsection{Determining the content of cost-effectiveness}

From experimental, it can be shown the resulting study of general frying system and the prototype. By the calculation and the comparison found that the user of the prototype fryer is a better way because the amount of fuel used for frying $1 \mathrm{~kg}$ of cricket is reduced to $16.8 \%$ compared to the general frying system. Since the prototype frying machine has a temperature controller, it saves the amount of gas used. As for regular pans, there is no temperature controller, causing the temperature of the oil in the container to be uncontrollable, and some gas evaporates with the environment while frying, causing waste of energy, as shown in Table 2.

Table 2. The comparison of cost-effectiveness from gas loss.

\begin{tabular}{|l|c|c|}
\hline & Pan & $\begin{array}{c}\text { Prototype frying } \\
\text { machine }\end{array}$ \\
\hline Fuel consumption & $0.347 \mathrm{~kg}$.gas $/ \mathrm{kg}$.product & $0.288 \mathrm{~kg}$.gas $/ \mathrm{kg}$.product \\
\hline The yield of products & $2.88 \mathrm{~kg}$.product $/ \mathrm{kg}$.gas & $3.46 \mathrm{~kg}$.product $/ \mathrm{kg}$.gas \\
\hline Cost price & $8.40 \mathrm{baht} / \mathrm{kg}$.product & $6.99 \mathrm{baht} / \mathrm{kg}$.product \\
\hline
\end{tabular}

Moisture or mass transfer during frying can be explained by using the product quantity analysis theory, the time required for frying is about $5 \mathrm{~min}$ per 1 round of frying. The test values are shown in Table 3. From Figure 3, it was found that the moisture content in cricket from liquid separation fryer is less than that. Due to the moisture in the cricket, when evaporated will reduce below the frying machine, which is cold water, causing the moisture to come out and not be able to combine with the meat of the cricket again. It results in lower moisture content in the product than a general frying pan.

From the development of this frying device, it was found that fuel consumption and cost price decrease while the yield of products increases. There are three originalities. First is the measure and control oil temperature, second is directly heat supply to bottom layer oil with self circulating from convection heat transfer, and last is using waste heat from the exhaust gas to heat upper layer oil. 
Table 3. Analysis of moisture content of cricket.

\begin{tabular}{|c|c|c|c|c|c|c|}
\hline \multirow{2}{*}{$\begin{array}{c}\text { No. of } \\
\text { cycles }\end{array}$} & $\begin{array}{c}\text { Weight } \\
\text { before } \\
\text { baking } \\
\text { (kg) }\end{array}$ & $\begin{array}{c}\text { Weight } \\
\text { after } \\
\text { baking } \\
\text { (kg) }\end{array}$ & $\begin{array}{c}\text { Moisture } \\
\text { content } \\
\mathbf{( \% w t )}\end{array}$ & $\begin{array}{c}\text { Weight } \\
\text { before } \\
\text { baking } \\
\text { (kg) }\end{array}$ & $\begin{array}{c}\text { Weight } \\
\text { after } \\
\text { baking } \\
\text { (kg) }\end{array}$ & $\begin{array}{c}\text { Moisture } \\
\text { content } \\
\text { (\%wt) }\end{array}$ \\
\hline 1 & 0.30 & 0.26 & 86.67 & 3.1 & 2.0 & 64.52 \\
\hline 2 & 0.30 & 0.27 & 90.00 & 3.0 & 2.8 & 93.33 \\
\hline 3 & 0.31 & 0.26 & 83.87 & 3.0 & 2.6 & 86.67 \\
\hline 4 & 0.29 & 0.24 & 82.75 & 2.9 & 2.4 & 82.76 \\
\hline 5 & 0.30 & 0.26 & 86.67 & 3.0 & 2.5 & 83.33 \\
\hline 6 & 0.30 & 0.27 & 90.00 & 3.1 & 2.4 & 77.42 \\
\hline 7 & 0.30 & 0.26 & 86.67 & 3.0 & 2.7 & 90.00 \\
\hline 8 & 0.29 & 0.25 & 86.21 & 3.0 & 2.5 & 83.33 \\
\hline 9 & 0.30 & 0.27 & 90.00 & 3.0 & 2.3 & 76.67 \\
\hline 10 & 0.28 & 0.24 & 85.71 & 3.0 & 2.6 & 86.67 \\
\hline 11 & 0.30 & 0.26 & 86.67 & 3.0 & 2.4 & 80.00 \\
\hline 12 & 0.29 & 0.25 & 86.21 & 3.0 & 2.5 & 83.33 \\
\hline 13 & 0.31 & 0.27 & 87.10 & 3.0 & 2.3 & 76.67 \\
\hline 14 & 0.30 & 0.26 & 86.67 & 3.0 & 2.4 & 80.00 \\
\hline 15 & 0.31 & 0.27 & 87.10 & 3.1 & 2.5 & 80.64 \\
\hline 16 & 0.30 & 0.26 & 86.67 & 3.0 & 2.4 & 80.00 \\
\hline 17 & 0.29 & 0.25 & 86.21 & 2.9 & 2.3 & 79.31 \\
\hline 18 & 0.31 & 0.28 & 90.32 & 3.0 & 2.4 & 80.00 \\
\hline 19 & 0.30 & 0.26 & 86.67 & 3.0 & 2.2 & 73.33 \\
\hline 20 & 0.30 & 0.26 & 86.67 & 3.0 & 2.5 & 83.33 \\
\hline 21 & 0.29 & 0.24 & 82.76 & 3.1 & 2.4 & 77.42 \\
\hline 22 & 0.29 & 0.23 & 79.31 & 2.9 & 2.2 & 75.86 \\
\hline 23 & 0.31 & 0.27 & 87.10 & 3.0 & 2.4 & 80.00 \\
\hline 24 & 0.30 & 0.25 & 83.33 & 3.1 & 2.2 & 70.97 \\
\hline
\end{tabular}

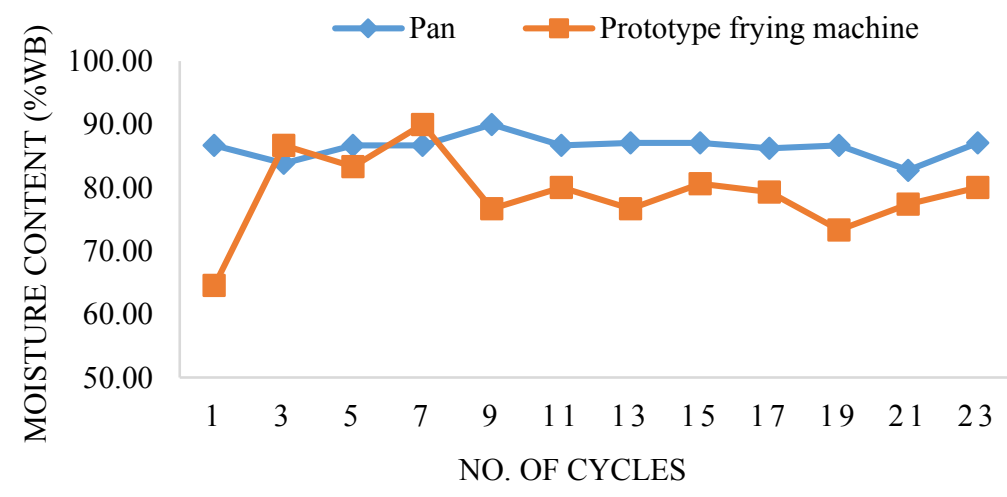

Fig. 3. Comparison of product moisture content between frying pans and frying machines. 


\section{Conclusions}

The evaluation of the separation layer efficiency of the separation layer fryer liquid that designed the gas control system with an electric system that can adjust the temperature and maintain the temperature of the frying constant at a temperature of $180^{\circ} \mathrm{C}$ : Separate liquids, using the amount of gas fuel for frying food, decreased by $16.8 \%$

The cost of manufacturing liquid separation fryers decreased by $20.6 \%$

The amount of cricket obtained from liquid separation fryer was more than $20.1 \%$

The product moisture content from the liquid separation fryer reduces more than the conventional pan. Crickets are crispy, not oil-based because it has less moisture accumulation than frying with a general pan. Prolonging the shelf life.

This research was supported by the Faculty of Engineering and Agro-Industry Maejo University and Innovation and Technology Assistance Program: projects that support technology development in the Thai industry, The National Science and Technology Development Agency.

\section{References}

1. I. S. Saguy, D. Dana, Journal of Food Engineering, 56, 143-152, (2003)

2. W. Sriviriyanupab, Revolutionary repeated frying oil by the test kit to consumer safety vendors can help, 131, 130-139, (2008)

3. W. Rangsathong, Food processing technology, 401, 500, (2003)

4. Nwadinobi. CP, Edeh. JC, Mejeh. KI, Journal of Applied Sciences and Environmental Management, Vol. 23 (7) 1279-1285 July, (2019)

5. B. Matthäus, European Journal of Lipid Science and Technology, 108(3), 200-211, (2006)

6. T. Pe'rez-Palacios, C. Petisca, S. Casal, I. M. Ferreira, International Journal of Food Sciences and Nutrition, 65(2), 212-218, (2014)

7. Fatma Nur Arslan, Ayça Nesibe Şapçı, Fatma Duru \& Huseyin Kara, International Journal of Food Properties, 20(3), 704-717, (2017)

8. T. Wongsiriamnuay, N. Panyoyai, S. Tantikul, Agric. Sci. J, 43(3), 179-182, (2012)

9. M. A. Mohamed, A. M. Hashim, O. S. Abu-Elyazeed, H. A. Elsayied, International Journal for Research in Applied Science \& Engineering Technology (IJRASET), 5,2971-2976, (2017)

10. N. Panyoyai, L. Petchaihan, T. Wongsiriamnuay, B. Hiransatitporn and T. Khamdaeng Mahasarakham International Journal of Engineering Technology, 5, 59-64, (2019)

11. L. Petchaihan, N. Panyoyai, T. Khamdaeng and T. Wongsiriamnuay, IOP Conf. Series: Earth and Environmental Science, 463, (2020)

12. C. Gertz, European Journal of Lipid Science and Technology, 106(11), 736-745, (2004)

13. V. R. Medeiros, F. Mestdagh, B. De Meulenaer, Food Chemistry, 133, 1138-1154, (2012)

14. A. Melo, O. Viegas, C. Petisca, O. Pinho, I. O. Ferreira, Journal of Agricultural and Food Chemistry, 56, 10625-10632, (2008)

15. N. Pongthep, Faculty of Business Administration Major in Business Engineering Management, Copyright from Rajamangala University of Technology Thanyaburi.L. T. De Luca, Propulsion physics, (2014) 